\title{
Coronary artery bypass in the ambulatory patient
}

\author{
Gladyston Luiz Lima Souto, ${ }^{a}$ Celme da Silva Caetano Júnior, ${ }^{a}$ José Bruno Silveira de Souza, ${ }^{a}$ Hanry Barros Souto, ${ }^{a}$ \\ Ary Getúlio de Paula Filho, ${ }^{\mathrm{b}}$ Marco Antonio Teixeira, ${ }^{\mathrm{C}}$ Márcio Roberto Moraes de Carvalho, ${ }^{\mathrm{c}}$ and \\ Antonio Carlos Botelho da Silva, ${ }^{\mathrm{c}}$ Itaperuna, Brazil
}

$\mathrm{I}$ $\mathrm{n}$ past decades, multiple organ dysfunctions ${ }^{1}$ provoked by cardiopulmonary bypass (CPB) have been studied. The short- and long-term results and higher cost of CPB changed the scientific focus, causing less harm to the patient and giving more emphasis to off-pump and minimally invasive surgery. Many articles appeared. Benetti ${ }^{2}$ and Karagoz and associates $^{3}$ contributed to the progress of minimally invasive direct coronary artery bypass (MIDCAB).

With further investigation, we believe in the possibility of performing a MIDCAB in the ambulatory patient. We therefore operated on a series of selected patients who were totally awake and without orotracheal intubation. They were discharged from the hospital within 24 hours after the operation.

\section{Methods}

Between January 2000 and May 2001, 20 patients were subjected to coronary artery bypass while fully awake, without the use of CPB or an orotracheal tube. All patients had a lesion in the left anterior descending artery, and none had important chronic pulmonary disease. Ages varied between 41 and 75 years, and the predominant sex was male. All patients were subjected to preoperative psychologic preparation.

\section{Operative Technique}

An epidural thoracic anesthetic was used. The $10-\mathrm{mL}$ solution was composed of $8 \mathrm{~mL}$ of $0.5 \%$ bupivacaine plus $2 \mathrm{mg}$ of morphine, injected by a needle at the T4 level, with posterior positioning of

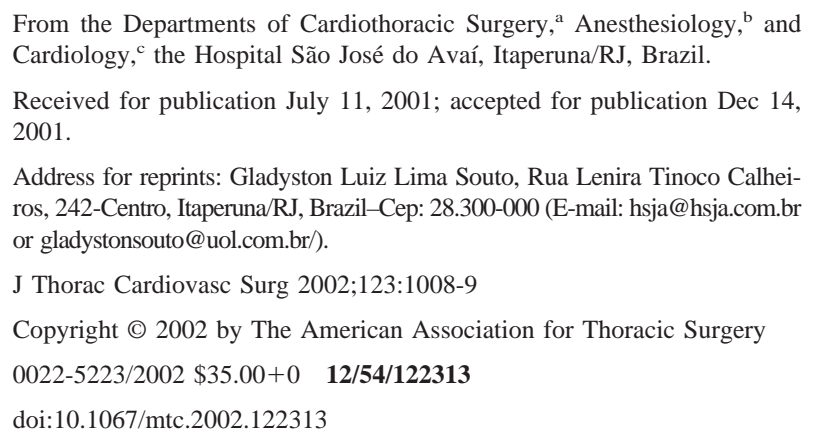

an 18-gauge catheter, and $1 \mathrm{~mL}$ of $0.5 \%$ bupivacaine that was injected for blocking in the second, third, fourth, and fifth left intercostal spaces. During the operation the patients were monitored through the arterial saturation with pulse oximetry, arterial gasometry before opening the thorax, and each 30 minutes after thoracotomy.

The access used was a thoracotomy in the fourth left intercostal space with the patients in the dorsal decubitus position, slightly turned to the right. The incision varied between 14 and $16 \mathrm{~cm}$. The left internal thoracic artery was dissected through the incision until its exit through the subclavian artery. The pericardium was opened longitudinally on the anterior face, having its edges well fixed to the edges of the wound. The anastomosis between the left internal thoracic artery and left anterior descending artery was performed with continuous sutures with the use of an intracoronary shunt and stabilizer. The left lung remained partially collapsed throughout the operation. After the pleural cavity was drained and the thoracic wall closed, to end the pneumothorax, we asked the patients to breathe deeply and cough until the lung was totally expanded.

\section{Results}

The 20 patients withstood the operation well. The pneumothorax time varied between 60 and 190 minutes. During the procedure there was no hemodynamic instability or arrhythmia. No important modifications occurred in the $\mathrm{Po}_{2}$ and $\mathrm{PCO}_{2}$ (Table 1). There were no electrocardiographic, echocardiographic, or enzymatic alterations that characterized postoperative necrosis or clinical pulmonary or radiologic alterations.

All but one patient were released within 24 hours.

\section{Discussion}

The techniques used in this group of patients are different because of the thoracic epidural block and the psychologic preparation, which permit the patients to be kept awake and able to talk the whole time. During the operation, when the patient breathes deeply the heart tends to dislocate to below the sternum. This will happen with less intensity when the pericardium is well fixed at the edges, principally on the sternal side, which does not permit dislocation. At the time of anastomosis, the anesthetist asks the patient to cooperate by avoiding deep breathing and moving. 
TABLE 1. Age (years), time of pneumothorax (minutes), blood saturation of oxygen (percent), and $\mathrm{PcO}_{2}$ (millimeters of mercury) before the opening of the thorax and every 30 minutes thereafter

\begin{tabular}{|c|c|c|c|c|c|c|c|c|c|c|c|c|c|c|c|c|}
\hline \multirow[b]{2}{*}{ Patients } & \multirow[b]{2}{*}{ Age } & \multirow{2}{*}{$\begin{array}{l}\text { Time of } \\
\text { pneumo. }\end{array}$} & \multicolumn{2}{|c|}{ Before } & \multicolumn{2}{|c|}{$30 \mathrm{~min}$} & \multicolumn{2}{|c|}{$60 \mathrm{~min}$} & \multicolumn{2}{|c|}{$90 \mathrm{~min}$} & \multicolumn{2}{|c|}{$120 \mathrm{~min}$} & \multicolumn{2}{|c|}{$150 \mathrm{~min}$} & \multicolumn{2}{|c|}{$190 \mathrm{~min}$} \\
\hline & & & Sat & $\mathrm{PcO}_{2}$ & Sat & $\mathrm{PcO}_{2}$ & Sat & $\mathrm{PcO}_{2}$ & Sat & $\mathrm{PcO}_{2}$ & Sat & $\mathrm{PcO}_{2}$ & Sat & $\mathrm{PcO}_{2}$ & Sat & $\mathrm{PcO}_{2}$ \\
\hline 1 & 51 & 92 & 99 & 37 & 98 & 40 & 97 & 41 & 97 & 41 & & & & & & \\
\hline 2 & 75 & 95 & 98 & 40 & 97 & 41 & 98 & 48 & 96 & 55 & & & & & & \\
\hline 3 & 69 & 85 & 98 & 40 & 97 & 40 & 98 & 44 & 97 & 46 & & & & & & \\
\hline 4 & 54 & 90 & 100 & 37 & 99 & 38 & 98 & 39 & 98 & 40 & & & & & & \\
\hline 5 & 56 & 80 & 99 & 37 & 97 & 40 & 97 & 42 & & & & & & & & \\
\hline 6 & 66 & 190 & 97 & 39 & 98 & 41 & 98 & 41 & 97 & 44 & 98 & 45 & 97 & 48 & 96 & 48 \\
\hline 7 & 64 & 70 & 98 & 38 & 98 & 43 & 98 & 43 & & & & & & & & \\
\hline 8 & 66 & 72 & 98 & 39 & 98 & 42 & 97 & 42 & & & & & & & & \\
\hline 9 & 73 & 75 & 97 & 40 & 96 & 42 & 96 & 46 & & & & & & & & \\
\hline 10 & 60 & 81 & 98 & 39 & 96 & 40 & 98 & 49 & 97 & 40 & & & & & & \\
\hline 11 & 72 & 95 & 98 & 40 & 98 & 42 & 99 & 46 & 98 & 46 & & & & & & \\
\hline 12 & 45 & 84 & 98 & 37 & 98 & 38 & 98 & 39 & 97 & 39 & & & & & & \\
\hline 13 & 68 & 100 & 97 & 38 & 97 & 43 & 97 & 42 & 98 & 43 & & & & & & \\
\hline 14 & 43 & 68 & 100 & 40 & 99 & 39 & 98 & 44 & & & & & & & & \\
\hline 15 & 41 & 60 & 100 & 40 & 99 & 39 & 98 & 42 & & & & & & & & \\
\hline 16 & 52 & 68 & 99 & 40 & 98 & 40 & 98 & 43 & & & & & & & & \\
\hline 17 & 52 & 77 & 99 & 39 & 97 & 43 & 97 & 44 & & & & & & & & \\
\hline 18 & 71 & 71 & 100 & 40 & 96 & 44 & 97 & 46 & & & & & & & & \\
\hline 19 & 65 & 68 & 98 & 37 & 97 & 42 & 96 & 47 & & & & & & & & \\
\hline 20 & 52 & 65 & 100 & 39 & 96 & 43 & 95 & 45 & & & & & & & & \\
\hline
\end{tabular}

Respiratory exercise is done as soon as the patient arrives in the intensive care unit. This is made easier by the type of anesthesia that permits the exercises to be pain free, avoiding complications. The epidural anesthesia can also reduce the incidence of postoperative arrhythmias ${ }^{4}$ and graft thrombosis. ${ }^{5}$ We believe that we can expand the revascularization to more vessels and use this technique for the surgical treatment of other conditions, such as lung and mediastinal diseases. A hospital discharge within 24 hours after the operation and sending the patient to a home care regimen for some days, which is ideal, avoids the inconveniences of atrial fibrillation that could eventually occur.

\section{Conclusion}

Pneumothorax did not cause postoperative morbidity and permitted good anastomosis. This technique can be done in a large number of patients. We believe that in the future, with more experience, it can be performed routinely in ambulatory patients.

\section{References}

1. Kirklin JK. Prospects for understanding and eliminating the deleterious effects of cardiopulmonary bypass. Ann Thorac Surg. 1991;51: 529-31.

2. Benetti FJ. Experience with surgery on the beating heart. In: Emery RW, editor. Technique for minimally invasive direct coronary artery bypass (MIDCAB) surgery. Philadelphia: Haley \& Belfus; 1997. p. 23-6.

3. Karagoz HY, Sommez B, Bakkaloglu B, Kurtoglu M, Erdinc M, Turkeli A, et al. Coronary artery bypass grafting in the conscious patient without endotracheal general anesthesia. Ann Thorac Surg. 2000;70:91-6.

4. Goldstein S, Dean D, Kim SJ, Grofsik J, Sillver P, Cody RP. A Survey of spinal and epidural techniques in adult cardiac surgery. $J$ Cardiothorac Vasc Anesth. 2001;15:158-66.

5. Rosenfeld BA, Beattie C, Christopherson R, Norris EJ, Frank SM, Breslow MJ, et al. The effects of different anesthesia regimens on fibrinolysis and the development of post operative arterial thrombosis. Anesthesiology. 1993;79:435-43. 